\title{
Construction of school-enterprise cooperation platform to improve the practical ability of professional degree master based on PBL mode
}

Qianqian Wang, Lijun Zhang, Dongxiao Wang, Shanshan Wang, Qun Hao

Qianqian Wang, Lijun Zhang, Dongxiao Wang, Shanshan Wang, Qun Hao, "Construction of school-enterprise cooperation platform to improve the practical ability of professional degree master based on PBL mode," Proc. SPIE 11143, Fifteenth Conference on Education and Training in Optics and Photonics: ETOP 2019, 1114321 (2 July 2019); doi: 10.1117/12.2524900 


\title{
Construction of school-enterprise cooperation platform to improve the practical ability of professional degree master based on PBL mode
}

\author{
Qianqian Wang*, Lijun Zhang, Dongxiao Wang, Shanshan Wang, Qun Hao

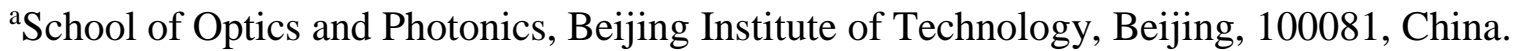

\begin{abstract}
Project-Based Learning (PBL) is an effective way to develop students' engineering practice skills. In order to cultivate the engineering personnel to meet the needs of society through school-enterprise cooperation, School of Optics and Photonics, Beijing Institute of Technology constructed a school-enterprise cooperation platform by utilizing the in-school resources, in which the in-school instructor is the leader and enterprise tutor is the link. Applying the PBL concept, the training mode for cultivating the engineering practical ability of professional degree master has been designed and investigated. The initial trial teaching and platform operation attempt was jointly carried out by School of Optics and Photonics with Beijing Advanced Innovation Center for Intelligent Robots and Systems (BAICIRS) of Beijing Institute of Technology, which verified the feasibility of the teaching model and provided the future teaching research direction and platform construction. There are important reference values for conclusions.
\end{abstract}

Keywords: Project-Based Learning, school-enterprise cooperation, professional degree master

\section{INTRODUCTION}

"Full-time professional degree master" is a new form of postgraduate program launched by the Ministry of Education (MOE) of China in 2009. After that the original quota of academic master has been gradually reduced, and the reduced was used to expand the scale of the full-time professional degree master (referred to as the professional master), in order to meet the urgent requirement of the national economic construction and social development for high-level professionals with innovative ability, entrepreneurial ability and practical ability.

In the past 10 years, the professional masters have achieved some useful experience, but there are still many key issues that require innovative ideas to find effective solutions. Aiming at the key points and difficulties of "how to implement school-enterprise cooperation and improve the engineering practice ability of professional master", School of Optics and Photonics (SOP) of Beijing Institute of Technology (BIT) try to use the resources of the school to build a school-enterprise cooperation platform. Guided by the requirements of enterprises and society, the educating mode for cultivating practical ability of professional master was explored based on PBL method.

The training goal of professional degree master is to make students become high-level applied talents who have a good command of fundamental theory and broad specialized knowledge in certain professional field, own the strong ability to solve practical problems and undertake the professional or management work, and have a good professional attainment ${ }^{[1]}$. Compared with the training goal of academic degree, which is established according to disciplines, directed by academic research, emphasizes theory and study, and mainly cultivates university teachers and researchers in scientific research institution, the educating mode of professional master is required to have distinct career orientation, industry-teachingresearch integration, engineering practicality and professional fields ${ }^{[2]}$.

Nevertheless, there are still many problems in the training of professional master, such as the unclear training goal for students, the homogenization of the training process between professional and academic masters, and the difficulty in implementing the cooperative training between school and enterprise ${ }^{[3]}$. "Some Opinions from the Ministry of Education about the Training of Full-time Professional Degree Graduate" was issued by MOE of China in 2009, which clearly put forward that "it is important that adequate and high-quality professional practice for the quality assurance of professional degree education", and stipulated that "the practice time of current undergraduate graduates is not less than one year in principle." However, during the training, how to put the school-enterprise collaborative training into practice, and give full play to the strengths of engineering experience and practical ability of enterprise tutor to guide and drive the cultivation of practical ability of the professional master has always been a difficult problem.

Fifteenth Conference on Education and Training in Optics and Photonics: ETOP 2019, edited by

Anne-Sophie Poulin-Girard, Joseph A. Shaw, Proc. of SPIE Vol. 11143, 1114321 - (C) 2019

SPIE, ICO, IEEE, OSA · CCC code: 0277-786X/19/\$18 · doi: 10.1117/12.2524900

Proc. of SPIE Vol. $111431114321-1$ 


\section{IDEA OF IMPROVING THE PRACTICAL ABILITY OF PROFESSIONAL DEGREE MASTER BASED ON PBL MODEL IN SCHOOL-ENTERPRISE COOPERATION}

\subsection{PBL method}

PBL method first appeared in McMaster University of Canada in the 1960s and applied in medical education at the beginning. It has been widely used in education of various majors. Problem-Based Learning, the earliest PBL form, has gradually evolved into another form-Project-Based Learning, which is also called PBL. Both of them have the remarkable characteristics of student-centered, which is conducive to mobilizing learning enthusiasm, cultivating self-study, team cooperation and practical abilities of students ${ }^{[4]}$.

PBL starts the completion of a design, model, device or computer simulation task by students, which is regarded as one of the final results. It focuses on the ability of the student team to solve problems. Usually, it requires students to apply the knowledge of various majors comprehensively and learn other relevant knowledge by themselves. And reports or/and oral presentations are submitted at the end of the project to summarize the research process ${ }^{[6]}$. Because the project of PBL usually comes from the open problems in engineering practice, this teaching method is more conductive to cultivate engineering talents who meet the actual demands of society.

\subsection{Platform Construction Idea}

In the cultivation of professional master, we feel that it is pretty difficult to promote the practice and internship of students in enterprises. Intimate connection is not established between enterprises and universities, and the actual participation of enterprises in this process is insufficient, which makes practice and internship become a mere formality. In view of this situation, based on "Innovative Education Platform for Optoelectronics and Information Graduates", we use the in-school teachers and education resources to explore and build a PBL practice platform in which enterprises and students can be directly connected.

The platform project is dominated by enterprises. The enterprises propose research projects for the selection of professional master according to the actual project. By use of PBL method, the in-school tutors are mainly responsible for guiding students to carry out project research. The enterprise provides an engineer for answering questions, docking and directing. In this way, students can achieve the purpose of internship and practice in school, and the implementation of the training links of professional master's practical ability has been guaranteed, while the burden of enterprises are decreased.

According to the step principle of PBL teaching method, the operation mode of the platform is divided into five steps:

Step 1: Raise a problem. The appropriate project or problem is selected from the actual project of the enterprise, and according to the knowledge base and basic ability of students, specific project or problem is raised and detailed project assignment is written combined with practice condition and practice cycle of the school platform. It's the initial condition for the implementation of engineering practice of professional master that a problem originating from engineering practice is proposed, which is also an important nature that distinguishes it from the research project of academic master. This practical project or problem needs to be targeted, pointed and guided, and it is necessary for final determination of project to discuss and negotiate repeatedly between the school tutor and the enterprise tutor.

Step 2: Organize a project team. The project assignment is published in the professional degree master, and the project team of 3-5 people is formed according to the principle of voluntary enrollment; the professional composition of team members is determined according to the specific requirements of the project about expertise, and the company tutor can be invited to participate in the selection or interview of the team members.

Step 3: Pre-project preparation. The school tutor introduces the background of the project, clarifies the project requirements, explains the time limitation and guides the team students to supplement relevant knowledge and skills according to the individual situation of them; this step is not only a process in which the project teams are familiar with each other and understanding the practical project, but also a procedure of inspiring students to think independently, think deeply and selflearning in PBL. On the basis of understanding the requirements of the project, the project team, under the guidance of the in-school tutor, proposes and establishes the practice and research plan of the project, which marks the completion of this step. 
Step 4: Project promotion. Regarding the project team as the main body and school tutor as the main instructor, and the enterprise tutor is responsible for answering questions and coordinating the necessary experimental conditions, and promoting the research and implementation of the project. It is necessary for project team to form a unified working system and regularly conduct face-to-face or remote discussions and reports with enterprise tutor. During the process of implementation, in-school tutor should fully stimulate the initiative of students, encourage them to think independently, and mainly play a role of guidance and supervision.

Step 5: Project summary and outcome transfer. At the end of the project cycle, the project team should organize the practice results, form the project research summary and detailed technical summary, hold a practical results release meeting (for presentation report and results demonstration), and cooperate with the enterprise to do a good job transfer.

After the completion of a project, in addition to the improvement of practical ability, students can also obtain the internship and practice certificate issued by both school and enterprise to enhance their employment competitiveness. Besides the technical achievements of the corresponding projects, the enterprise can also gain the potential talent pool needed to take the preemptive opportunities in the talent recruitment market.

\section{EXPLORATION ON THE OPERATION OF SCHOOL-ENTERPRISE COOPERATION PLATFORM}

From April to June, 2018, according to the above PBL idea and steps, an exploration on the operation of school-enterprise platform was performed. We chose "Beijing Advanced Innovation Center for Intelligent Robots and Systems" (BAICIRS) as the partner. This center was among the first batch of 13 advanced innovation centers accredited by Beijing Municipal Education Commission. Aiming at national major demands and international research fronts, BAICIRS focuses on the development of intelligent service robots for family services, assistance for the elderly, science education, space services and other applications around the field of intelligent robots and systems research.

According to the expertise and actual requirements of the cooperation units, we put forward an engineering practical problem "Design and Development of Testing Software for Front-end Actuator System of Surgical Assistant Robot in Narrow Space". The specific contents of this problem are as follows.

(1) The front-end actuator of the surgical robot is an important part of the minimally invasive surgical robot system, which directly acts on the tissues or organs inside the patient's body to complete specific tasks.

(2) The actuator generally has at least four degrees of freedom to complete the opening, pitching, tumbling and rolling of the forceps.

(3) This project involves two kinds of surgical actuators. The mechanism dynamics test is carried out through the test system to verify the feasibility of mechanism design and technique, and the data of motion accuracy, joint coupling relationship and continuous deformation characteristics are obtained.

Firstly, an in-school tutor was selected. She and her partner "Beijing Advanced Innovation Center for Intelligent Robots and Systems" The teaching practice based on PBL method to improve the practical ability of professional master was carried out, and the first operation exploration of school-enterprise cooperation platform was also achieved.

Beijing Advanced Innovation Center for Intelligent Robots and Systems

The in-school tutor we selected is a full-time teacher of Beijing Institute of Technology and has several cooperation projects with surgery robot in narrow space team of BAICIRS and are mainly responsible for the research and development of product of control software and related algorithms in the project. Therefore, this tutor is more familiar with the situation of the cooperation unit, and has rich engineering experience in the professional field. She has strong practical ability and the conditions and basis for effective guidance in engineering practice of students.

The student who participated in this teaching practice project was enrolled in September, 2017 and will graduate with a professional degree master in 2019. After this stage of learning, he has a certain practical ability in the development of optical-electronic-machinery integration products and mastered the basic methods of scientific study. During the threemonth practice period, according to the developing project, many problems need to be solved urgently in the actual project were proposed by enterprise tutor. Through actively communicating with the production team of narrow space surgical robots in many aspects, and deeply understanding and investigating the student, in-school tutor refined and formalized the 
practical problems raised by the enterprise tutor according to the knowledge and ability base of student and the practice condition and practice cycle of the school platform, thus a practical project which is most suitable for the student was putting forward. Meanwhile, the project assignment (including implementation rules, points for attention, results and time nodes) was written by the enterprise tutor, and the project assignment was further modified and the knowledge and ability points were disassembled by in-school tutor. Finally, the student independently designed a set of testing software for the surgical robot in narrow space, and independently designed the GUI interface of the software. At the same time, he assisted the enterprise tutor to complete the image testing work for the front-end actuator of the surgical robot.

Finally, the enterprise tutor gave students a comprehensive evaluation from the project completion, knowledge system, ability manifestation, transfer of results, report summary and so on, and all aspects of the evaluation were excellent. This student believe that the practice of three months has allowed him to deepen into the real engineering practice and greatly improve himself in all aspects.

\section{CONCLUSION}

From the preliminary effect of the operation of the school-enterprise cooperation platform based on PBL mode to improve the practical ability of professional master, the platform can support the application of PBL method in the engineering practice link according to the expected mode. Combining the self-evaluation of enterprise tutors, school tutors and students, the school-enterprise cooperation training mode on the basis of platform based on the school resources can contribute to strengthen the practical ability of professional degree master.

However, this exploration practice is only a qualitative and beneficial attempt. There is a lack of quantitative comparison of the improvement of the student's practical ability before and after, and horizontal comparison evaluation with other equivalent students. The sample size of only one student is not sufficient to support the expected goal of talents training.

Through this attempt, it is recognized that the following three points should be grasped in the next step of the construction work of the platform operation mode:

(1) Taking the employment of professional degree master as the traction, first of all, teaching research should be achieved according to the survey of demand of the employers for talents, and the scale should be expanded and widely implemented. A one-stop training mode of professional master in the form of "employment-research subject of dissertation-engineering practice project", which meets the "occupational orientation" requirement of professional degree education, should be created with the demand of enterprise personnel as the leading role;

(2) Close docking between teachers and enterprises should be established, engineering experience and practical ability of in-school tutors should be strengthened, and a group of "double-type" teachers who focus on engineering research should be reserved. The teacher guidance system in which the in-school tutor is the leader and the enterprise tutor is the link should be constructed to meet the requirements of "Industry-University-Research coordination" for professional degree education.

(3) The engineering practice training link based on PBL method should be carefully designed to form a practical course for professional master. With the curriculum as the carrier and relying on the platform resources in school, the engineering training link based on PBL method should be included in the training plan, and the "engineering practicality" is highlighted on the basis of satisfying the "professional field".

\section{REFERENCES}

[1] Ministry of Education, "Some Opinions of the Ministry of Education on the Training of Full-time Professional Degree Graduate," 19 March 2009,

<http://www.moe.edu.cn/srcsite/A22/moe_826/200903/t20090319_82629.html> (19 March 1997). 
[2] Huajun Liu, Xianyun Li, "Tarining Attributes and Ways of Professional Degree Graduate: A Case Study of Electrical Engineering in Nanjing Institute of Technology," Academic Degrees \& Graduate Education, 4, 16-21 (2014).

[3] LiHong Li, Gang Liu, "Research on the Cooperative Training Mechanism of Full-time Professional Degree Graduate with Double Tutors," Academic Degrees \& Graduate Education, 34, 38-41 (2018).

[4] Ziming Feng, etc., "Development of Postgraduate Innovation Design Ability Based on PBL," Journal of Heilongjiang University of Technology, 18, 22-29 (2018).

[5] JieDan Liao, Reflections on the Role of Teachers in PBL Mode of Aalborg University, " Education Modernization, 46, 14-15 (2018).

[6] Aditya Johri, Barbara M. Olds., [Cambridge Handbook of Engineering Education Research], Cambridge University Press, New York, 145-146 (2014). 